\title{
Influence of climate change on Desertification in Qaidam Basin
}

\author{
Huang Jingtao ${ }^{1, a}$, Jiang yingxiang ${ }^{1, b}$ \\ ${ }^{1}$ Kunming University of Science and Technology Kunming China \\ ahuangjingtao.happy@163.com, ${ }^{b} 512400943 @ q q . c o m$
}

Keywords: Precipitation;desertification;Basin

Abstract. In this paper, the data of soil erosion from Mangya, Lenghu, Xiaowouhuo, Golmud, Ulan and Da six Dan Chai ecological monitoring stations monitoring data ranged from 2005 to 2015, and MODIS and GIMMS remote sensing monitoring NDVI values from 1985 to 2015. This thesis researched characteristics of the soil erosion in the Qaidam Basin. At this time, The author researched Qaidam Basin Erosion (block) and dune movement characteristics, as well as the changes of the precipitation and desertification area. The impact of climate change on Desertification in Qaidam Basin was analyzed. The result indicated that evaporation volume paralleled with desertification.

\section{Introduction}

Desertification refers to the land degradation in arid, semi arid and sub-humid arid regions caused by various factors, including climate variability and human activities [1-3]. Desertification is the third major environmental problem in the world. Also, it is one of the most prominent ecological problems in China, and seriously harms the sustainable development of Chinese desertification areas [4-6]. Qaidam Basin is one of the areas suffering the most serious desertification in China, and the ecological environment there is quite fragile. With the progress of the western basin and the increase of population in the basin area, the contradictions between construction and development, population and land, and resources development and environmental protection have appeared in front of people to different degrees. These contradictions will become increasingly prominent and concentrated as time passing by. It has seriously affected the sustainable development of the economy and the production and life of people in basin area and even in Qinghai Province. Therefore, it has important practical and theoretical significance to study the development of desertification in the area and put forward the prevention and control measures.

\section{Materials and methods}

This research adopted the observation data of soil erosion (accumulation) in six ecological monitoring stations in Mangya, Lenghu, Xiaozaohuo, Golmud, Uhlan, and Da Qaidam, the observation data of mobile dunes in Da Qaidam from 2005 to 2015, and MODIS and GIMMS remote sensing monitoring NDVI values from 1985 to 2015.

The average of the observation data of soil erosion (accumulation) in six ecological monitoring stations in Mangya, Lenghu, Xiaozaohuo, Golmud, Uhlan, and Da Qaidam represents the soil erosion (accumulation) condition in Qaidam Basin. According to the desertification index defined by Qinghai Province Remote Sensing Monitoring Center, MODIS monitoring NDVI value $<0.08$ is defined as the desertification index. Based on the correlation between GIMMS and MODIS, GIMMS monitoring NDVI value $<0.035$ is defined as the desertification index. The desertification area of Qaidam Basin is extracted by Arcgis software. 


\section{Results and discussion}

The change features of wind erosion (accumulation) and dune movement. The wind accumulation value decreased from 2005 to 2015 , decreasing by $0.61 \mathrm{~cm}$ every ten years. As shown in Figure 2.46a, the wind accumulation value changed significantly before 2011, and the difference between the maximum and minimum was $1.15 \mathrm{~cm}$. After 2011 , the wind accumulation value changed stably, presenting a continuous decreasing trend. The difference between the maximum and minimum was $0.33 \mathrm{~cm}$. The wind erosion value decreased from 2005 to 2015 , decreasing by $0.99 \mathrm{~cm}$ every ten years. As shown in Figure. 1, the wind erosion value changed significantly from 2005 to 2009 , and the average was $5.67 \mathrm{~cm}$. From 2010 to 2015 , the wind erosion value decreased rapidly, and the average was $4.67 \mathrm{~cm}$.

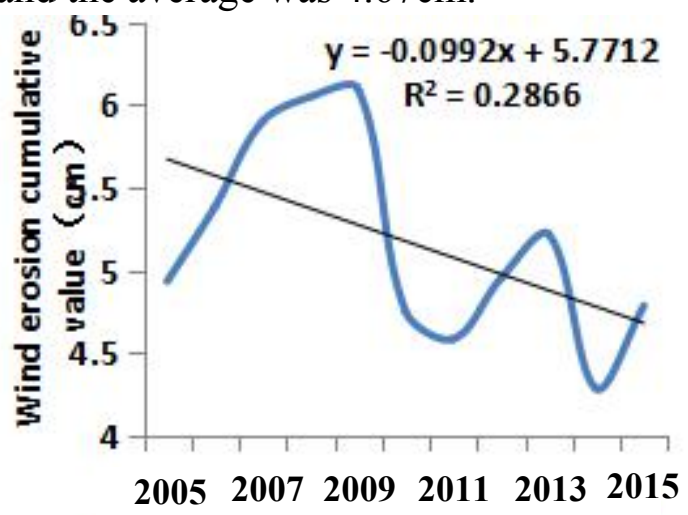

(a)

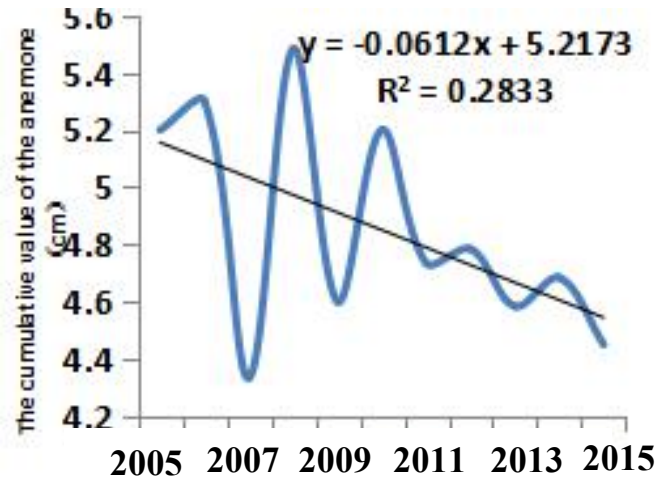

(b)

Figure. 1 Changing curves of wind accumulation (a)and wind erosion (b) in Qaidam Basin from 2005 to 2015

Change features of desertification area. Based on the MODIS monitoring NDVI value, the NDVI value less than 0.08 is defined as the desertification region. According to the NDVI value of each lattice in Qaidam Basin from 1985 to 2015, the annual desertification area was extracted (Figure. 2). As shown in the figure. 1, the desertification face value in Qaidam Basin decreased from 2005 to 2015 , decreasing by $4228 \mathrm{~km}^{2}$ every ten years. Particularly, the desertification area substantially decreased since 2011. The average desertification area from 2005 to 2009was $9424.79 \mathrm{~km}^{2}$, and decreased to $7759.244 \mathrm{~km}^{2}$ from 2011 to 2015.

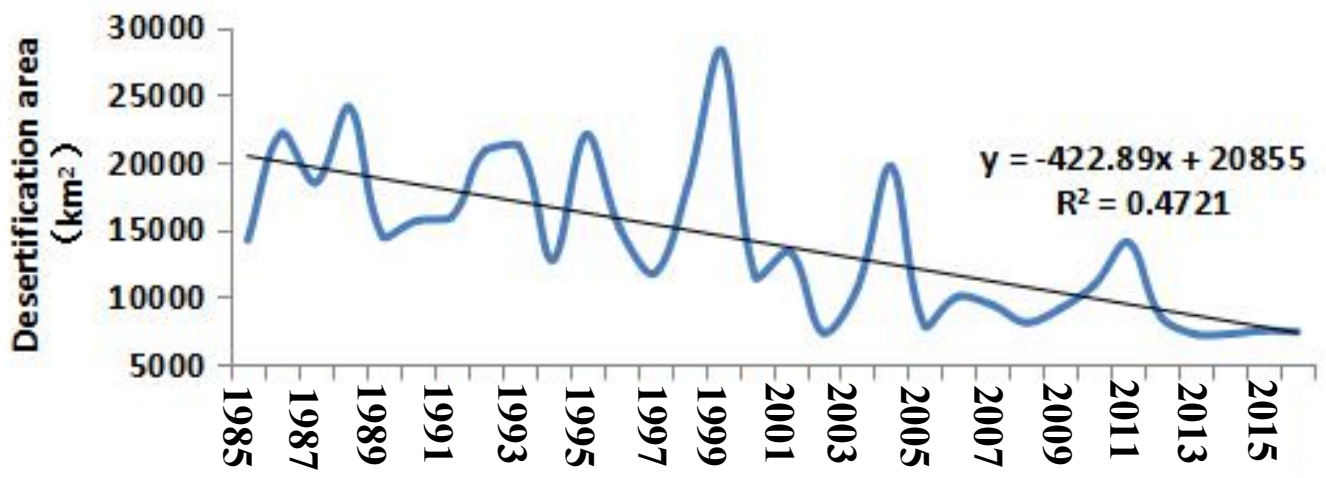

Figure. 2 Change curve of desertification area in Qaidam Basin during 2005-2015 
Influence of Climate Change on Desertification Area. Temperature, precipitation and evaporation are important meteorological factors of land desertification. The average temperature in Qaidam Basin significantly increased from 1985 to 2015, with the temperature increase rate of 0.60/10a. The annual precipitation presented an increasing trend, and the trend coefficient was $9.89 \mathrm{~mm} / 10 \mathrm{a}$. The annual evaporation showed a decreasing trend, and the trend coefficient was 10.7 $\mathrm{mm} / 10 \mathrm{a}$.

Because of the closed terrain in the basin terrain and the limited drainage area, its drainage has the inland characteristics, and is all small rivers flowing to the center of the basin floor. The river fostering the oasis in Qaidam Basin mainly relies on the ice and snow melt and precipitation in Kunlun Mountain. In recent years, due to the rising temperature, melting of glaciers is increased, and a large number of ice and snow in Kunlun Mountains begin to melt. Surface runoff and groundwater entering the oasis increased significantly. Owing to a large number of water supplies, plants began to grow in the desert area near river. Part of the desert steppe obtains the water supply, leading to the lush growth of vegetation. The desert region has been transformed to oasis.

According to the change trend of temperature, precipitation, evaporation and desertification area in Figure 3, the average annual temperature and annual precipitation are negatively correlated with the desertification area change, and the correlation coefficients are 0.66 and 0.47 , respectively. There is a significantly positive correlation between evaporation and desertification area, and the correlation coefficient is 0.52 . From 1985 to 2015, under the common effects of climate warming, increased precipitation and slightly decreased evaporation, the desertification area of Qaidam Basin was decreased. Particularly, the desertification area decreased significantly since 2001. 


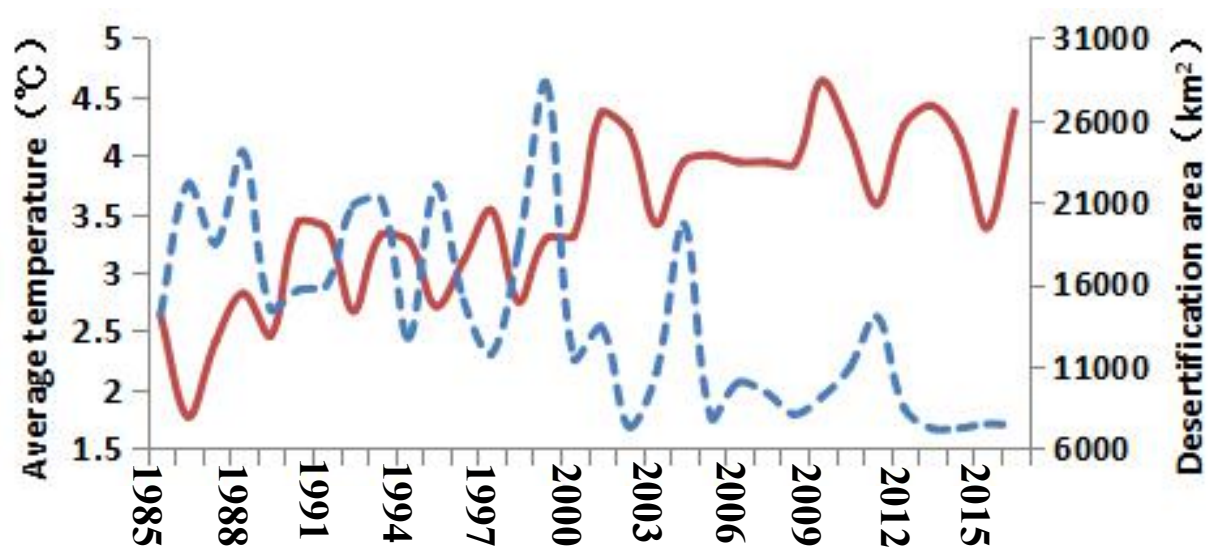

(a)

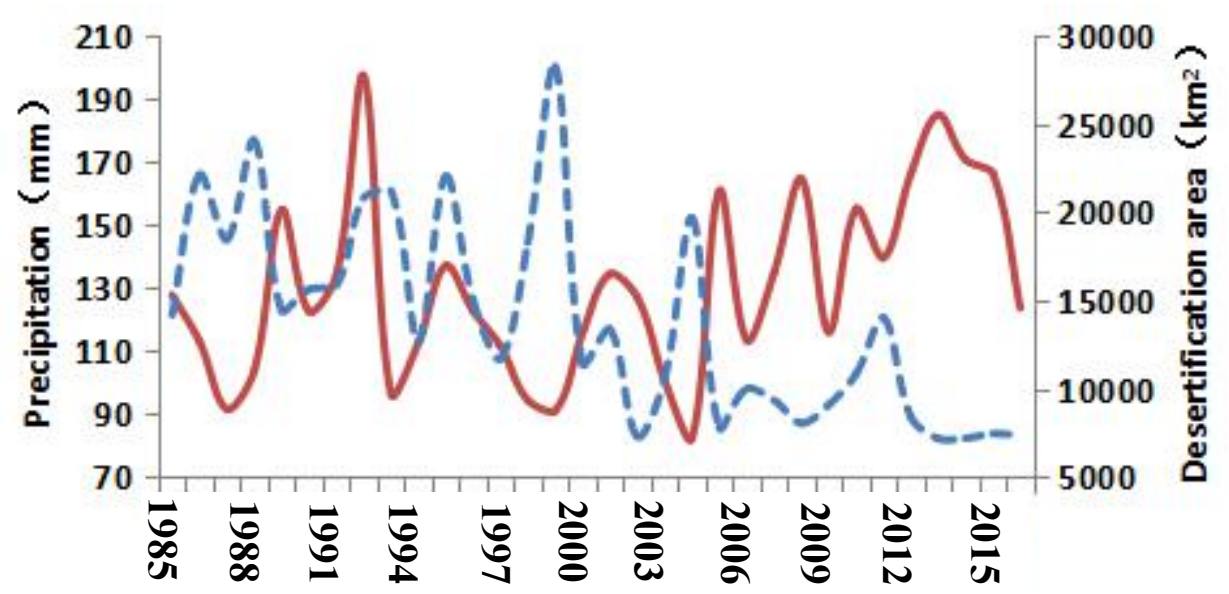

(b)

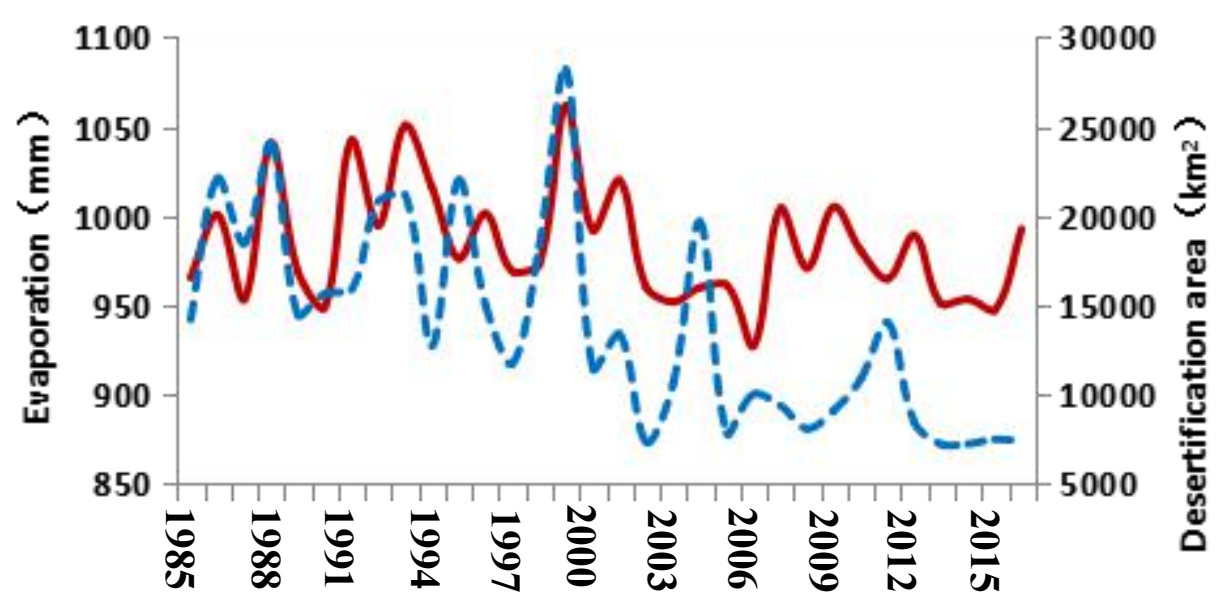

(c)

Figure. 3 Variation curves of temperature (a), precipitation (b), evaporation (c) and desertification area in 1985-2015

Countermeasures to the adaption of desertification to climate change.

As an important resource development area in China, Qaidam Basin is in the face of fragile ecological environment and serious land desertification. Also, it is one of the areas with the fastest desertification speed in China. Therefore, on the premis eof accelerating the economy and resource 
development in Qaidam Basin, it is necessary to protect the ecological environment and prevent from the development of desertification.

1.Protect the original vegetation, and prevent the expansion of desertification. First of all, the expansion and development of desertification should be prevented by establishing ecological protection zone, setting up and improving the corresponding protection laws and regulations, and protecting the existing sand vegetation. Secondly, adjust energy structure, increase investment and technology promotion efforts, make full use of solar energy and wind energy, and change the energy results in rural areas. Meantime, strictly control the new ecological damage caused by resource development.

2.Implement key projects to prevent and control desertification. Establish ecological control project investment mechanism, implement urban environmental protection planning and reasonable layout of industrial structure, and accelerate the construction of urban ecological protection engineering and ecological demonstration project.

3.Gradually change the existing mode of agricultural production. Establish the ecological agriculture production mode, improve the utilization ratio of water resources, give priority to the establishment of farmland shelterbelt system and windbreak system, and prevent the adverse effects of agricultural production on ecological environment.

\section{Conclusion}

The wind accumulation value and wind erosion accumulation value decreased from 2005 to 2015, decreasing by $0.61 \mathrm{~cm}$ and $0.99 \mathrm{~cm}$ every ten years, respectively. From 1985 to 2015, the desertification area decreased, with a decrease of $4228 \mathrm{~km} 2$ every ten years. Particularly, the desertification area decreased greatly since 2011. The annual average temperature and annual precipitation are negatively correlated with the desertification area. The evaporation is positively correlated with the desertification area. In the RCP4.5 scene, the desertification area significantly decreases from 2016 to 2050 , decreasing by $139 \mathrm{~km} 2$ every ten years. After 2050 , the desertification area increases by $134 \mathrm{~km} 2$ every ten years.

\section{References}

[1] Desertification Prevention and Control Office of the Ministry of Forestry of People's Republic of China. United Nations Convention on the Prevention and Control of Desertification in Countries with Severe Drought and / or Desertification, particularly in Africa [M]. Beijing: China Forestry Publishing House, 1994.

[2] United Nations.United Nations Convention to CombatDesertifica-tion in Those Countries Experiencing Serious Drought and/orDe-sertification Particularly in Africa[R]. 1994.

[3] Zhu Zhenda. Concept, Cause and Control of Desertification in China [J]. Quaternary Sciences, 1998, 18(2): 145-155.

[4] The sixth Research Group of Prevention and Control of Desertification (land degradation) in China. Research on Prevention and Control of Desertification (land degradation) in China [M]. Beijing: China Environmental Science Pres, 1998.

[5] Zhu Zhenda. The Status and Prospect Desertification in China [J]. ACTA Geographical SINICA (Supplement), 1994, 49: 650-657.

[6] Dong Guangrong, Wu Bo, Ci Longjun. Status, Cause and Countermeasures of Desertification in China [J]. Journal of Desert Research, 1999, 19(4): 318-332. 